\title{
Changes in the quality of life of patients with Blount's disease undergoing simultaneous bilateral varus deformity correction with the use of the llizarov method.
}

Type

Research paper

\section{Keywords}

Ilizarov method, Genu varum, Blount Disease, External Fixator, Limb deformity

\begin{abstract}
Introduction

Blount's disease is a growth disorder of the proximal tibia, which leads to the varus deformity and internal rotation of this bone. The treatment is mainly surgical and involves proximal tibial osteotomy and deformity correction. The aim of this study was to assess the change in the quality of life of patients with tibia vara deformity who underwent correction via the llizarov method.

\section{Material and methods}

A total of 23 Blount's disease patients who had undergone bilateral varus deformity correction with the llizarov method were included in this study. The following parameters were assessed retrospectively: duration of treatment with llizarov frames, baseline and postoperative values of the medial proximal tibial angle (MPTA) and mechanical axis deviation (MAD). The quality of life was assessed with a Short Form (SF)-36 survey.
\end{abstract}

\section{Results}

The study population comprised 13 females and 10 males (mean age of 28.43), in whom the llizarov fixators were kept for an average duration of 106.65 days. MAD values diminished significantly after the surgery. We also observed significant increases in the MPTA values. The SF-36 scores increased across all of the questionnaire's domains, which indicates a significant improvement in the postoperative quality of life.

\section{Conclusions}

Simultaneous bilateral correction of the varus deformity with llizarov external fixators is a safe and effective treatment method. It helps reduce pain and improve gait, which translates to improving the quality of life in all its aspects. The duration of treatment depends to a large extent on the degree of patient cooperation, their attitude, and self-discipline. 


\section{TITLE PAGE:}

Title: Changes in the quality of life of patients with Blount's disease undergoing simultaneous bilateral varus deformity correction with the use of the Ilizarov method

Authors: Łukasz Szelerski 1 *, Sławomir Żarek 1, Radosław Górski 1, Karol Mochocki 1, Ryszard Górski 1 , Andżelika Pajchert-Kozłowska 2, Paweł Małdyk 1, Piotr Morasiewicz 2,3

Authors Affiliation:

1- Medical University of Warsaw, Department of Orthopedics and Musculoskeletal

Traumatology, Lindeya 4, 02-005 Warsaw, Poland

2- Wroclaw Medical University, Department and Clinic of Orthopaedic and Traumatologic

Surgery, Borowska 213, 50-556 Wroclaw, Poland

3- Department of Orthopaedic and Trauma Surgery, University Hospital in Opole, Institute of Medical Sciences, University of Opole, Witosa 26, 41-405, Opole, Poland.

* Corresponding author: Łukasz Szelerski, Medical University of Warsaw, Department of Orthopedics and Musculoskeletal Traumatology, Lindeya 4, 02-005 Warsaw, Poland, Tel.: +48 796850304, e-mail: L.szelerski@gmail.com

\section{Acknowledgments:}

There was no Conflict of Interest for all authors.

There was no sources of founding 


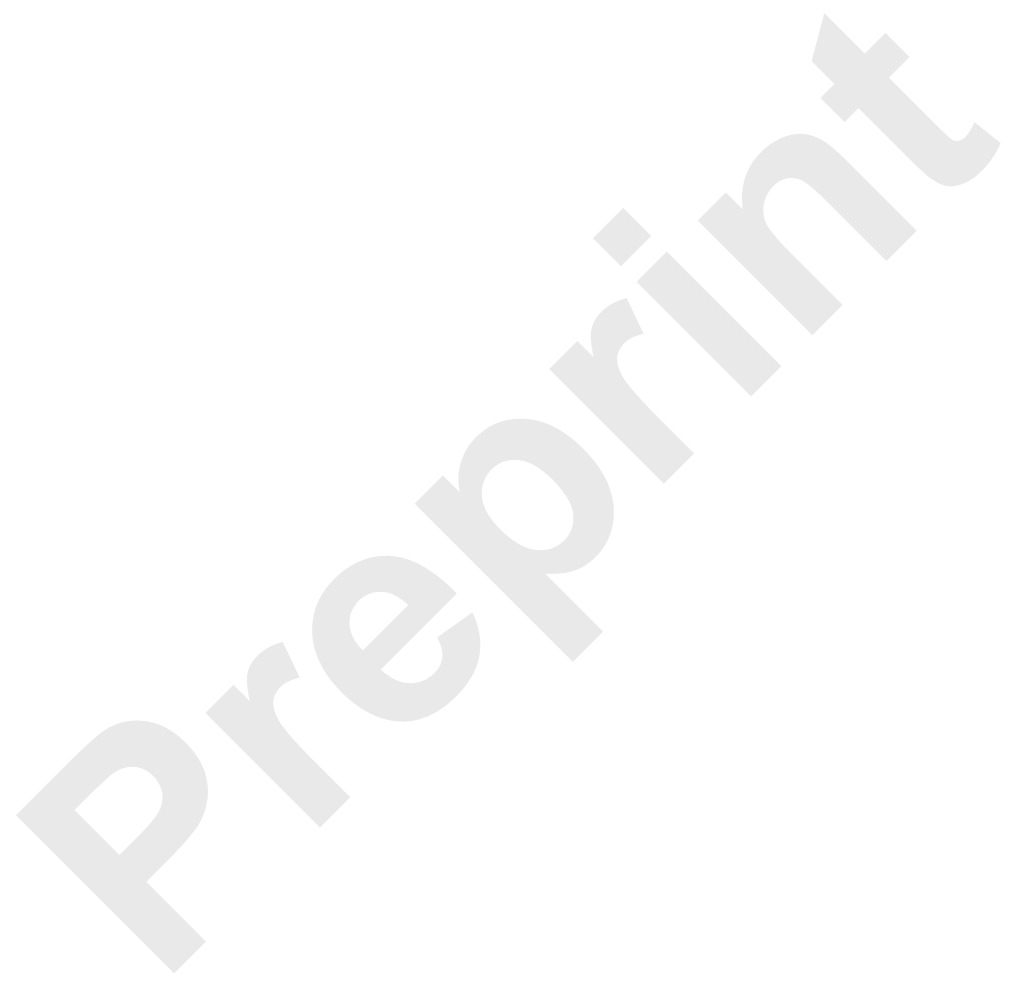


Abstract:

2

3

4 Blount's disease is a growth disorder of the proximal tibia, which leads to the varus

5 deformity and internal rotation of this bone. The treatment is mainly surgical and involves proximal tibial osteotomy and deformity correction. The aim of this study was to assess the

change in the quality of life of patients with tibia vara deformity who underwent correction via the llizarov method.

Material and methods:

A total of 23 Blount's disease patients who had undergone bilateral varus deformity correction with the llizarov method were included in this study. The following parameters were assessed retrospectively: duration of treatment with llizarov frames, baseline and postoperative values of the medial proximal tibial angle (MPTA) and mechanical axis deviation (MAD). The quality of life was assessed with a Short Form (SF)-36 survey. Results:

The study population comprised 13 females and 10 males (mean age of 28.43), in whom the Ilizarov fixators were kept for an average duration of 106.65 days. MAD values diminished significantly after the surgery. We also observed significant increases in the MPTA values. The SF-36 scores increased across all of the questionnaire's domains, which indicates a significant improvement in the postoperative quality of life.

Conclusions:

Simultaneous bilateral correction of the varus deformity with Ilizarov external fixators is a safe and effective treatment method. It helps reduce pain and improve gait, which translates 
to improving the quality of life in all its aspects. The duration of treatment depends to a large extent on the degree of patient cooperation, their attitude, and self-discipline.

6

Introduction:

\section{(1)}

Blount's disease is a growth disorder affecting the proximal tibia, which leads to a varus

deformity and internal tibial rotation(1). (Figure 1) In the year 1937, Blount distinguished

two clinical variants of this deformity, noting their different age of onset. The infantile, or early-onset, form typically develops during the first three years of life and is usually bilateral.

The adolescent, or late-onset, form develops at the age of 11 years or later(2, 3).

Although the etiology of Blount's disease is unknown, there has been research into its possible correlation with obesity and vitamin D3 deficiency $(3,4)$. Left untreated, Blount's disease leads to progressive limb deformity, with the associated mechanical overload of the medial knee compartment and the consequent development of knee osteoarthritis( 3,5$)$.

Conservative management has been unsuccessful. The surgical approaches currently used for varus deformity correction are tibial hemiepiphysiodesis (in patients whose growth plates have not fused yet) and corrective osteotomy $(3,6)$. Deformity correction may be achieved either intraoperatively with the use of osteotomy and metal implants or gradually, for example with an Ilizarov fixator(7-9). One particularly common technique is proximal 


\section{.} 2 3

tibial osteotomy. Normalizing the limb mechanical axis reduces the medial overload exerted on the proximal tibia and contributes towards relieving pain and improving gait(10, 11).

There have been literature reports describing various surgical techniques and the successful correction achieved(7, 12-15). Our study aimed to analyze the effect of surgical correction on the quality of life in patients with Blount's disease. We believe that lower limb deformity correction has a beneficial impact on the patients' physical and psychological wellbeing, emotions, and social interactions. The scarcity of available reports on assessing the quality of life in patients following lower limb deformity correction prompted us to perform such assessments. We believe that in addition to the commonly adopted geometric criteria used in assessing the shape of the lower limbs, the patients' subjective impression of their condition and any changes in that impression following surgery should be considered.

The purpose of this study was to assess the change in the quality of life of patients with tibia vara deformity who underwent intraoperative bilateral reconstructive surgery combined with gradual postoperative correction via the Ilizarov method.

Material and methods:

Our study included 23 patients who had undergone bilateral corrective surgery with the Ilizarov method for the varus deformity associated with Blount's disease. The inclusion criteria were: the accessibility of the patient's complete medical and radiographic records, follow-up period of $>1$ year, the patient's informed consent, and Short Form (SF)-36 questionnaire completion both prior to and one year after surgery. The exclusion criteria 
71 were bilateral limb deformities due to other causes (e.g. metabolic diseases such as

72 hypophosphatemic rickets or Paget's disease of bone, the lack of an informed consent, and

73 incomplete radiographic records. The study was approved by the Local Institutional Review

74 Board.

75 The study was conducted in 13 females (57\%) and 10 males (43\%) at the mean age of 28.43

76 (age range: 7-60 years) with the mean duration of post-surgery llizarov fixator treatment of

77 106.65(range: 31-199 days).

78 The mean follow-up period was 6.1 years (range: $1,5-10,2$ years, SD- 2,88 years).

79 We evaluated the duration of treatment with an Ilizarov external fixator, the baseline and

80 postoperative values of the medial proximal tibial angle (MPTA) and mechanical axis

81 deviation (MAD). The patients' quality of life was assessed with SF-36 questionnaires(16).

82 Preoperative planning was conducted based on panoramic radiographic images of the lower

83 limbs. Obtaining reliable radiographic images requires a correct patient positioning, with the

84 patellae facing directly forward. This helps accurately determine the extent of deformity.

85 Corrective surgery is indicated when the MAD exceeds $15 \mathrm{~mm}$.

86 The obtained radiographic images were used to mark the MPTAs and the center of rotation

87 of angulation (CORA) and to plan the position of the llizarov rings. The surgical procedures

88 were conducted under regional anesthesia. During the initial part of the procedure, a $0.5-\mathrm{cm}$

89 segment of the fibula was resected. Then, a three-ring llizarov external fixator was mounted,

90 with the hinges positioned over the predetermined CORA. Once the fixator was in place,

91 proximal tibial corticotomy was performed through a small incision. Initial deformity

92 correction was performed under fluoroscopy. The same steps were repeated for the other

93 limb.(Figure 2) 
The patients were mobilized on the first postoperative day and taught how to walk with full weight-bearing with the use of forearm crutches. The patients were discharged on postoperative day $3-5$, depending on the progress in their ambulation.

The initial outpatient follow-up assessments were scheduled in 2-week intervals, and the later ones in 4-week intervals. The patients underwent rehabilitation, with exercise therapy targeted at the ankle and knee joints to improve the range of motion and prevent contractures. Over time, as they were making progress in their mobility, the patients were encouraged to walk without crutches or walkers.

The decision to remove llizarov fixators was made once clinical and radiographic signs of bone union were observed. Firstly, the fixator was removed from one of the limbs, and the patient was advised to avoid any weight-bearing on that limb for 2-4 weeks. Then, one month later, the other fixator was removed. This protocol made it easier for patients to walk, while simultaneously helping add more weight onto the bone regenerate in the other limb during the final weeks of treatment.

The statistical analysis to test the research hypothesis was conducted with STATISTICA 13.3 (StatSoft Polska sp.z.o.o, Cracow, Poland) software. This software helped obtain the basic descriptive statistics and conduct the final analysis. The mean differences between groups were calculated with a mixed-design analysis of variance model (ANOVA). The level of significance was set at $\alpha=0.05$.

Results: 
Statistical analysis of the MAD values prior to and after left and right knee surgery revealed considerable differences. However, it was only the effect of treatment (i.e. the main effect) that proved significant $\left(F(1,44)=514.12, p<0.001, \eta^{2}=0.92\right)$, whereas the interaction effect showed no statistical significance $\left(F(1,44)=0.16, p=0.691, \eta^{2}<0.01\right)$. Postoperative MAD values were significantly lower than baseline values, with this difference observed both in the left and right limbs, with no differences between the sides observed at either time point (before or after surgery) (Graph1).

Statistical analysis of the left and right MPTA values before and after surgery also demonstrated significant differences; however, also solely in terms of the main effect $(F(1$, 44) $\left.=514.12, p<0.001, \eta^{2}=0.92\right)$, with the interaction effect showing no statistical significance $\left(F(1,44)=0.16, p=0.691, \eta^{2}<0.01\right)$. The postoperative MPTA values, both in the left and right limb, were significantly higher, with no differences between the sides (left vs. right) at neither time point (Graph2).

Changes in the quality of life were analyzed based on SF-36 survey scores. The SF-36 survey includes 8 domains relating to the specific aspects of daily life, including physical and psychological wellbeing, pain, and social functioning.

\section{"Physical functioning"}

The analysis of baseline and postoperative scores in the female and male groups showed a significant increase in scores, irrespective of the patient $\operatorname{sex}\left(F(1,21)=51.62, p<0.001, \eta^{2}=\right.$ $0.71)$, with no significant interaction effect $\left(F(1,21)=0.02, p=0.890, \eta^{2}<0.01\right)$ and hence no intergroup differences at the individual time points. 
141 The scores in this domain of the survey were significantly higher after surgery, irrespective

142 of the $\operatorname{sex}\left(F(1,21)=48.47, p<0.001, \eta^{2}=0.70\right)$, with the interaction effect showing no

143 significance $\left(F(1,21)=0.37, p=0.548, \eta^{2}=0.02\right)$. Due to violated assumption of

144 homogeneity of variance and normal distribution, the calculations were repeated with a

145 series of nonparametric tests - The conclusions this yielded were the same, i.e. there were

146 no significant differences between the group of males and females at any study time point.

147 Both groups were found to be similar in terms of baseline scores, postoperative scores, and

148 the values of score changes.

150 "Role limitations due to emotional problems"

151 In this case also the main effect of the procedure turned out to be significant, with the

152 postoperative scores significantly higher than the baseline ones $\left(F(1,21)=6.75, p=0.017, \eta^{2}\right.$

$153=0.24)$, and was observed both in the male and female groups, between which there were 154 no differences at neither time point, i.e. there was no significant effect of interaction $(F(1$, $\left.15521)=1.75, p=0.200, \eta^{2}=0.08\right)$.

156

"Energy/Fatigue"

158 Analysis of pre- and postoperative scores in the female and male groups showed a significant increase in scores, irrespective of the $\operatorname{sex}\left(F(1,21)=30.76, p<0.001, \eta^{2}=0.59\right)$, with no significant interaction effect $\left(F(1,21)=0.36, p=0.552, \eta^{2}=0.02\right)$, which indicates that the baseline and postoperative scores and the resulting score changes were similar in both study groups. 
165 The ANOVA results, like in the case of the survey domains presented above, showed a 166 statistical significance of the effect of treatment (main effect) $\left(F(1,21)=34.68, p<0.001, \eta^{2}\right.$

$167=0.62)$, with no significance of the interaction effect of $\operatorname{sex}\left(F(1,21)=0.92, p=0.348, \eta^{2}=\right.$ 0.04). Both groups showed a significant increase in scores for this domain, with no differences between the groups observed either at baseline or after the procedure.

171 "Pain"

172 Pain scores also showed a significant effect of treatment (main effect) $(F(1,21)=55.07, p<$ $1730.001, \eta^{2}=0.72$; with the scores significantly higher at the postoperative time point) observed in both male and female groups; with no significant inter-group differences at the two time points (no significant interaction effect) $\left(F(1,21)=1.21, p=0.284, \eta^{2}=0.05\right.$ ).

178 Analysis of the baseline and postoperative scores in the male and female groups showed a 179 significant increase, irrespective of the $\operatorname{sex}\left(F(1,21)=32.56, p<0.001, \eta^{2}=0.61\right)$, whereas 180 the interaction effect was not significant $\left(F(1,21)=1.46, p=0.241, \eta^{2}=0.06\right)$. These results 181 indicate that both groups showed a similar change in scores, and that their scores were 182 similar at individual time points.

\section{"General Health"}

185 The general health domain scores were significantly higher after the procedure, irrespective of the $\operatorname{sex}\left(F(1,21)=46.06, p<0.001, \eta^{2}=0.69\right)$, with the interaction effect showing no significance $\left(F(1,21)=0.94, p=0.344, \eta^{2}=0.04\right)$. Both study groups showed similar baseline scores, postoperative scores, and change in scores. 
"Health Change"

191 The health change domain also showed a significant effect of treatment $(F(1,21)=23.74, p<$

$\left.1920.001, \eta^{2}=0.53\right)$, with significantly higher scores at the second time point; however, the 193 interaction effect was not significant $\left(F(1,21)<0.01, p=0.999, \eta^{2}<0.01\right)$, which indicates 194 that the baseline and postoperative scores and the change in scores were similar in both 195 study groups.

196 The results are presented in Table 3.

197 Statistical analysis of the obtained SF-36 scores revealed an improved quality of life in all the 198 assessed patients. In addition, the achieved MPTA and MAD fell within the physiological 199 ranges for those parameters.

200

201

202

203

204

Discussion:

205

Orthopedic surgery outcome assessments more and more commonly include a subjective

206 component in the form of patient-reported outcomes measures (PROMs)(17). These 207 measures use specific questionnaires in which patients describe various aspects of their 208 physical, emotional, and social wellbeing without supervision by a physician. PROM analysis 209 helps assess the impact of individual procedures on pain severity and quality of life (18-20).

211 External fixators have been used for lower limb deformity correction for a long time(21-24).

212 Distraction osteogenesis helps achieve good outcomes in the treatment of congenital and 
213 acquired deformities $(9,10,25-28)$. Restoration of a neutral mechanical axis in the lower limb 214 prevents destruction of the articular cartilage, reduces pain, and facilitates an effective gait 215 pattern.

216 Bilateral genu varum deformity may develop in adolescents and adults as a result of Blount's 217 disease, rickets, or skeletal dysplasia(9).

218 There have been a number of reports on treatment outcomes in unilateral varus deformity 219 correction. However, reports on the simultaneous treatment of both limbs are scarce. Kim et al. described their results in 48 patients treated with Ilizarov fixators for bilateral genu 221 varum deformities due to various skeletal dysplasias(28). Those authors observed a mean 222 lengthening amount of $7.4 \mathrm{~cm}$ and the MAD reduction by $9.3 \mathrm{~mm}$. Park et al. performed 21 223 genu varum correction surgeries in 11 patients(10). Those authors achieved a mean 224 reduction in the MAD from $28.3 \mathrm{~mm}$ to $5.8 \mathrm{~mm}$. Feldman et al. treated 19 patients (22 225 tibiae) with Taylor spatial frames (TSF)(29). As a result, the MAD was reduced from $53.9 \mathrm{~mm}$ 226 to $1.4 \mathrm{~mm}$, and the mechanical MPTA was increased from 71.4 degrees to 87.9 degrees. Li et 227 al. reported treatment outcomes in 14 patients with obesity(30). The postsurgical MAD 228 value was improved from $90 \mathrm{~mm}$ to $10 \mathrm{~mm}$ and the mechanical MPTA from 66 degrees to 88 229 degrees.

230 One of the few studies on bilateral correction of the genu varum deformity was conducted 231 by Özkul et al(9). Those authors performed a gradual correction in 25 patients (50 tibiae) 232 with the use of Smart frame fixators and achieved a considerable improvement in the MAD, 233 mechanical MPTA, and posterior proximal tibial angle (PPTA) values. Those authors 234 emphasized that a gradual correction lowers the risk of such complications as peroneal 235 nerve injury, compartment syndrome, and delayed union. 
236 Our observations do not support this theory, since in our experience it is the valgus

237 deformity correction surgery that is associated with a high risk of peroneal nerve injury. The

238 pressure inside the lateral fascial compartment of the leg does not rise significantly during

239 genu varum correction. Thus, our team routinely performs initial varus deformity correction

240 in an intraoperative setting. We believe that this helps the patient to adapt more rapidly to

241 walking with use of forearm crutches and facilitates rehabilitation. Erect X-ray images help

242 verify the achieved correction, and the degree of patient satisfaction determines whether

243 we decide to further increase or decrease the extent of correction.

244 In the topic of corrective surgeries of the tibia, the issue that continues to provoke 245 discussion is whether or not and, if so, how to perform fibular osteotomy(6, 9, 29). Sachs et 246 al. achieved similar outcomes with and without fibular osteotomy in a small group of 247 patients undergoing deformity correction(6). Those authors emphasized the risk of peroneal 248 nerve injury depending on the exact location of fibular osteotomy. Eidelman et al. 249 performed 10 corrective surgeries without fibular osteotomy in 8 children(31). MAD 250 correction was achieved via the use external fixators, with the hinges positioned at the level 251 of the proximal tibiofibular joint. Those authors did not observe any neurological 252 complications. Dilawaiz et al. performed 39 corrective surgeries in children(32). After the 253 procedure, two of the patients developed transient sensory and motor dysfunction of the 254 hallux. An analysis of all the cases with neurological complications revealed that the surgeon 255 had performed fibular osteotomy too close to the area deemed to be high-risk according to 256 Kirgis and Albrecht(33). Studies in cadavers define the high risk zone as the area located 6 $257 \mathrm{~cm}$ to $13 \mathrm{~cm}$ distal to the fibular head(33, 34).

258 Our team routinely performs fibular osteotomy during corrective surgeries of the tibia. We use a posterolateral approach at the middle third or at the level of the middle and distal 
thirds of the fibula. Fibular osteotomy is performed in an oblique, nearly sagittal, rather than

261

262

263

264

273 Our findings are similar to or slightly better than those reported in literature. Detailed data

274 are presented in Table 1.

275 Analysis of changes in the quality of life showed a significant improvement in all domains of

276 the SF-36 survey, irrespective of the patient's sex. All patients experienced improved pain

277 levels along with an improved emotional status and interpersonal relations. The possibility

278 of functioning in the society and engaging in any occupation with no disability-associated

279 limitations were an added value following treatment completion.

280 Simultaneous surgery of both lower limbs means that the patient must begin to get up and

281 bear full weight on the limbs immediately after the surgery. Our observations indicate that

282 despite the use of the same technique in both limbs, almost always some differences

283 emerge in terms of time of bone healing, rapidity of regaining function, and the possibility of 
full weight-bearing. There seems to be an association between the patient's attitude and

285 pain tolerance and the duration of treatment with an Ilizarov fixator. We suspect a correlation between the type of the patient's personality and his or her psychological condition, and the duration of bone healing and self-discipline in regaining limb function.

This issue requires further studies and conducting evaluations and analyses, particularly at the time of qualifying patients for surgery.

Bone regenerate formation also depends on factors that are independent of the patient's attitude towards the therapeutic process. Comorbidities, such as diabetes mellitus or kidney disease, and certain medications may delay bone healing(37). Our team makes careful, rational judgments when qualifying patients for corrective surgeries and always considers potential obstacles in the treatment process. Due to its minimally invasive character, the Ilizarov method is dedicated for those patients in whom wound healing delay can be anticipated.

One limitation of our study was the small size of the analyzed study group. This was due to the specific character of the evaluated condition but also the rarity of bilateral deformity correction. Many centers perform corrective osteotomy surgeries with the use of implanted plates, which require reduced weight-bearing on the limb for several weeks after surgery.

The patients who receive llizarov fixators can ambulate with full weight-bearing from postoperative day one; therefore, it is possible to correct both limbs simultaneously without rendering the patient bedridden for long periods of time.

\section{Conclusions:}

Simultaneous varus deformity correction with the use of llizarov external fixators is a safe and effective treatment method. It helps reduce pain and improve gait, which translates to 
improving the quality of life in all its aspects. The duration of treatment depends to a large

extent on the degree of patient cooperation, attitude, and self-discipline. (Figure 3)

Conflict of Interest: The authors declare that they have no conflict of interest

Ethical approval: This article does not contain any studies with human participants or animals performed by any of the authors.

1. Janoyer M. Blount disease. Orthop Traumatol Surg Res. 2019;105(1S):S111-S21.

2. Birch JG. Blount disease. J Am Acad Orthop Surg. 2013;21(7):408-18.

3. de Pablos J, Arbeloa-Gutierrez L, Arenas-Miquelez A. Update on treatment of adolescent Blount disease. Curr Opin Pediatr. 2018;30(1):71-7.

4. Sabharwal S. Treatment of Infantile Blount Disease: An Update. J Pediatr Orthop. 2017;37 Suppl 2:S26-S31.

5. Mayer SW, Hubbard EW, Sun D, Lark RK, Fitch RD. Gradual Deformity Correction in Blount Disease. J Pediatr Orthop. 2019;39(5):257-62.

6. Sachs O, Katzman A, Abu-Johar E, Eidelman M. Treatment of Adolescent Blount Disease Using Taylor Spatial Frame With and Without Fibular Osteotomy: Is There any Difference? J Pediatr Orthop. 2015;35(5):501-6.

7. Griswold B, Gilbert S, Khoury J. Opening Wedge Osteotomy for the Correction of Adolescent Tibia Vara. Iowa Orthop J. 2018;38:141-6.

8. Shiha A, El-Deen MA, Khalifa AR, Kenawey M. Ilizarov gradual correction of genu varum deformity in adults. Acta Orthop Belg. 2009;75(6):784-91.

9. Özkul B, Çamurcu Y, Sokucu S, Yavuz U, Akman YE, Demir B. Simultaneous bilateral correction of genu varum with Smart frame. J Orthop Surg (Hong Kong). 2017;25(2):2309499017713915.

10. Park YE, Song SH, Kwon HN, Refai MA, Park KW, Song HR. Gradual correction of idiopathic genu varum deformity using the Ilizarov technique. Knee Surg Sports Traumatol Arthrosc. 2013;21(7):1523-9.

11. Saw A, Phang ZH, Alrasheed MK, Gunalan R, Albaker MZ, Shanmugam R. Gradual correction of proximal tibia deformity for Blount disease in adolescent and young adults. J Orthop Surg (Hong Kong). 2019;27(3):2309499019873987.

12. Clarke SE, McCarthy JJ, Davidson RS. Treatment of Blount disease: a comparison between the multiaxial correction system and other external fixators. J Pediatr Orthop. 2009;29(2):103-9.

13. Burton A, Hennrikus W. Complete Closing Wedge Osteotomy for Correction of Blount Disease (Tibia Vara): A Technique. Am J Orthop (Belle Mead NJ). 2016;45(1):16-8. 
14. Fitoussi F, Ilharreborde B, Lefevre Y, Souchet P, Presedo A, Mazda K, et al. Fixatorassisted medial tibial plateau elevation to treat severe Blount's disease: outcomes at maturity. Orthop Traumatol Surg Res. 2011;97(2):172-8. 15. Jain MJ, Inneh IA, Zhu H, Phillips WA. Tension Band Plate (TBP)-guided Hemiepiphysiodesis in Blount Disease: 10-Year Single-center Experience With a Systematic Review of Literature. J Pediatr Orthop. 2020;40(2):e138-e43.

16. Kłosiński M, Tomaszewski KA, Tomaszewska IM, Kłosiński P, Skrzat J, Walocha JA. Validation of the Polish language version of the SF-36 Health Survey in patients suffering from lumbar spinal stenosis. Ann Agric Environ Med. 2014;21(4):866-70. 17. Wilson I, Bohm E, Lübbeke A, Lyman S, Overgaard S, Rolfson O, et al. Orthopaedic registries with patient-reported outcome measures. EFORT Open Rev. 2019;4(6):357-67. 18. Rolfson O, Eresian Chenok K, Bohm E, Lübbeke A, Denissen G, Dunn J, et al. Patientreported outcome measures in arthroplasty registries. Acta Orthop. 2016;87 Suppl 1:3-8. 19. Dams OC, van den Akker-Scheek I, Diercks RL, Wendt KW, Bosma E, van Raaij TM, et al. The recovery after Achilles tendon rupture: a protocol for a multicenter prospective cohort study. BMC Musculoskelet Disord. 2019;20(1):69.

20. Lyman S, Lee YY, Franklin PD, Li W, Cross MB, Padgett DE. Validation of the KOOS, JR: A Short-form Knee Arthroplasty Outcomes Survey. Clin Orthop Relat Res. 2016;474(6):146171.

21. Gubin A, Borzunov D, Malkova T. Ilizarov Method for Bone Lengthening and Defect Management Review of Contemporary Literature. Bull Hosp Jt Dis (2013). 2016;74(2):14554.

22. Gubin AV, Borzunov DY, Marchenkova LO, Malkova TA, Smirnova IL. Contribution of G.A. Ilizarov to bone reconstruction: historical achievements and state of the art. Strategies Trauma Limb Reconstr. 2016;11(3):145-52.

23. Jordan CJ, Goldstein RY, McLaurin TM, Grant A. The evolution of the llizarov technique: part 1: the history of limb lengthening. Bull Hosp Jt Dis (2013). 2013;71(1):89-95. 24. Goldstein RY, Jordan CJ, McLaurin TM, Grant A. The evolution of the llizarov technique: part 2: the principles of distraction osteosynthesis. Bull Hosp Jt Dis (2013). 2013;71(1):96-103.

25. Vaidya SV, Song HR, Lee SH, Suh SW, Keny SM, Telang SS. Bifocal tibial corrective osteotomy with lengthening in achondroplasia: an analysis of results and complications. J Pediatr Orthop. 2006;26(6):788-93.

26. Morasiewicz P, Morasiewicz L, Stępniewski M, Orzechowski W, Morasiewicz M, Pawik $\iota$, et al. Results and biomechanical consideration of treatment of congenital lower limb shortening and deformity using the llizarov method. Acta Bioeng Biomech. 2014;16(1):13340.

27. Watanabe K, Tsuchiya H, Sakurakichi K, Yamashiro T, Matsubara H, Tomita K. Treatment of lower limb deformities and limb-length discrepancies with the external fixator in Ollier's disease. J Orthop Sci. 2007;12(5):471-5.

28. Kim SJ, Cielo B, Song SH, Song HR, Song SY. Gradual bilateral genu varum correction in skeletal dysplasia using the llizarov method. J Orthop Sci. 2011;16(4):405-12.

29. Feldman DS, Madan SS, Ruchelsman DE, Sala DA, Lehman WB. Accuracy of correction of tibia vara: acute versus gradual correction. J Pediatr Orthop. 2006;26(6):794-8.

30. Li Y, Spencer SA, Hedequist D. Proximal tibial osteotomy and Taylor Spatial Frame application for correction of tibia vara in morbidly obese adolescents. J Pediatr Orthop. 
31. Eidelman $M$, Bialik V, Katzman A. The use of the Taylor spatial frame in adolescent Blount's disease: is fibular osteotomy necessary? J Child Orthop. 2008;2(3):199-204. 32. Dilawaiz Nadeem R, Quick TJ, Eastwood DM. Focal dome osteotomy for the correction of tibial deformity in children. J Pediatr Orthop B. 2005;14(5):340-6. 33. Kirgis A, Albrecht S. Palsy of the deep peroneal nerve after proximal tibial osteotomy. An anatomical study. J Bone Joint Surg Am. 1992;74(8):1180-5. 34. Elgafy $H$, Ebraheim NA, Shaheen PE, Yeasting RA. Extensor hallucis longus innervation: an anatomic study. Clin Orthop Relat Res. 2002(398):245-51.

402 35. Adili A, Bhandari M, Giffin R, Whately C, Kwok DC. Valgus high tibial osteotomy. 403 Comparison between an llizarov and a Coventry wedge technique for the treatment of 404 medial compartment osteoarthritis of the knee. Knee Surg Sports Traumatol Arthrosc. 405 2002;10(3):169-76.

406 36. Fadel M, Hosny G. The Taylor spatial frame for deformity correction in the lower 407 limbs. Int Orthop. 2005;29(2):125-9.

408 37. Nicholson JA, Makaram N, Simpson A, Keating JF. Fracture nonunion in long bones: A 409 literature review of risk factors and surgical management. Injury. 2020. 


\begin{tabular}{|c|c|c|c|c|}
\hline & \multicolumn{2}{|c|}{ Before surgery } & \multicolumn{2}{|c|}{ After Surgery } \\
\hline & $M$ & $S D$ & $M$ & $S D$ \\
\hline \multicolumn{5}{|l|}{ All patients $(N=23)$} \\
\hline SF-36 physical functionig & 50,22 & 22,54 & 86,52 & 13,52 \\
\hline SF-36 role limitations due to physical health & 32,61 & 36,49 & 88,04 & 21,15 \\
\hline SF-36 role limitations due to emotional problems & 50,73 & 43,65 & 79,71 & 37,26 \\
\hline SF-36 energy/fatigue & 53,70 & 14,56 & 73,04 & 16,22 \\
\hline SF-36 emotional well-being & 51,48 & 17,98 & 76,87 & 16,27 \\
\hline SF-36 pain & 45,11 & 19,95 & 82,50 & 13,84 \\
\hline SF-36 social functioning & 57,07 & 23,48 & 83,15 & 18,31 \\
\hline SF-36 general health & 33,26 & 22,44 & 66,52 & 16,06 \\
\hline SF-36 health change & 36,96 & 19,76 & 61,96 & 18,26 \\
\hline \multicolumn{5}{|l|}{ Women $(n=13)$} \\
\hline SF-36 physical functionig & 50,00 & 22,17 & 86,92 & 13,00 \\
\hline SF-36 role limitations due to physical health & 34,62 & 34,67 & 94,23 & 10,96 \\
\hline SF-36 role limitations due to emotional problems & 43,60 & 47,89 & 84,62 & 37,55 \\
\hline SF-36 energy/fatigue & 54,23 & 16,94 & 75,38 & 16,52 \\
\hline SF-36 emotional well-being & 50,15 & 19,71 & 79,08 & 16,75 \\
\hline SF-36 pain & 40,77 & 19,75 & 82,88 & 15,06 \\
\hline SF-36 social functioning & 59,62 & 24,56 & 80,77 & 20,17 \\
\hline SF-36 general health & 29,62 & 23,14 & 66,92 & 18,43 \\
\hline SF-36 health change & 34,62 & 19,20 & 59,62 & 19,20 \\
\hline \multicolumn{5}{|l|}{$\operatorname{Men}(n=10)$} \\
\hline SF-36 physical functionig & 50,50 & 24,20 & 86,00 & 14,87 \\
\hline SF-36 role limitations due to physical health & 30,00 & 40,48 & 80,00 & 28,38 \\
\hline SF-36 role limitations due to emotional problems & 60,01 & 37,84 & 73,33 & 37,85 \\
\hline SF-36 energy/fatigue & 53,00 & 11,60 & 70,00 & 16,16 \\
\hline SF-36 emotional well-being & 53,20 & 16,34 & 74,00 & 16,03 \\
\hline SF-36 pain & 50,75 & 19,76 & 82,00 & 12,85 \\
\hline SF-36 social functioning & 53,75 & 22,86 & 86,25 & 16,08 \\
\hline
\end{tabular}


SF-36 general health

SF-36 health change
38,00

40,00

21,76

66,00

13,29

$M$-średnia, $S D$ - odchylenie standardowe
21,08

65,00

17,48 


\section{Graph 1}

Marginal means along with the 95\% confidence interval for the variable MAD before and after surgery for the left and right sides.

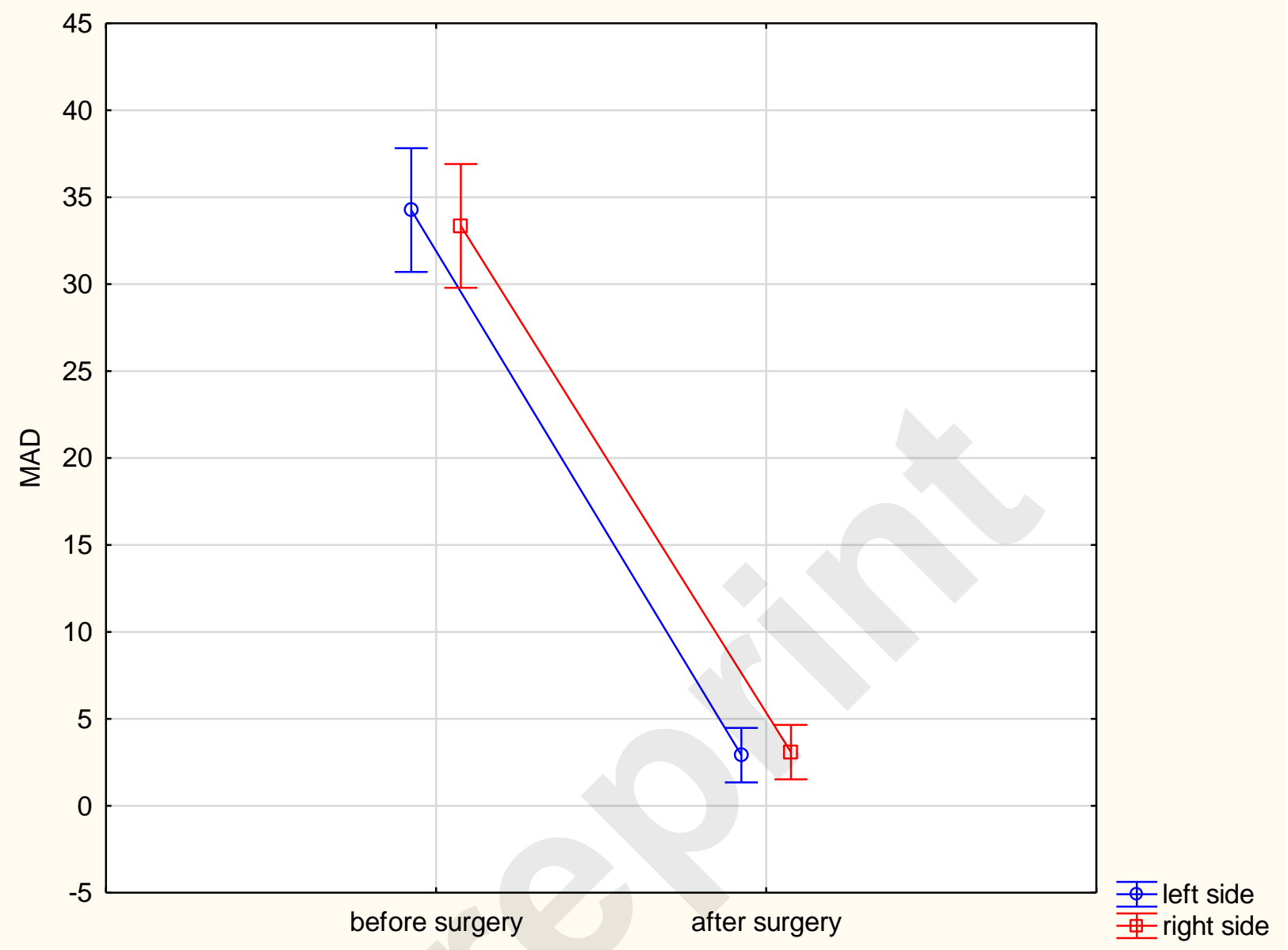




\section{Graph 2}

Marginal means along with the 95\% confidence interval for the variable medial proximal tibial angle before and after surgery for the left and right sides

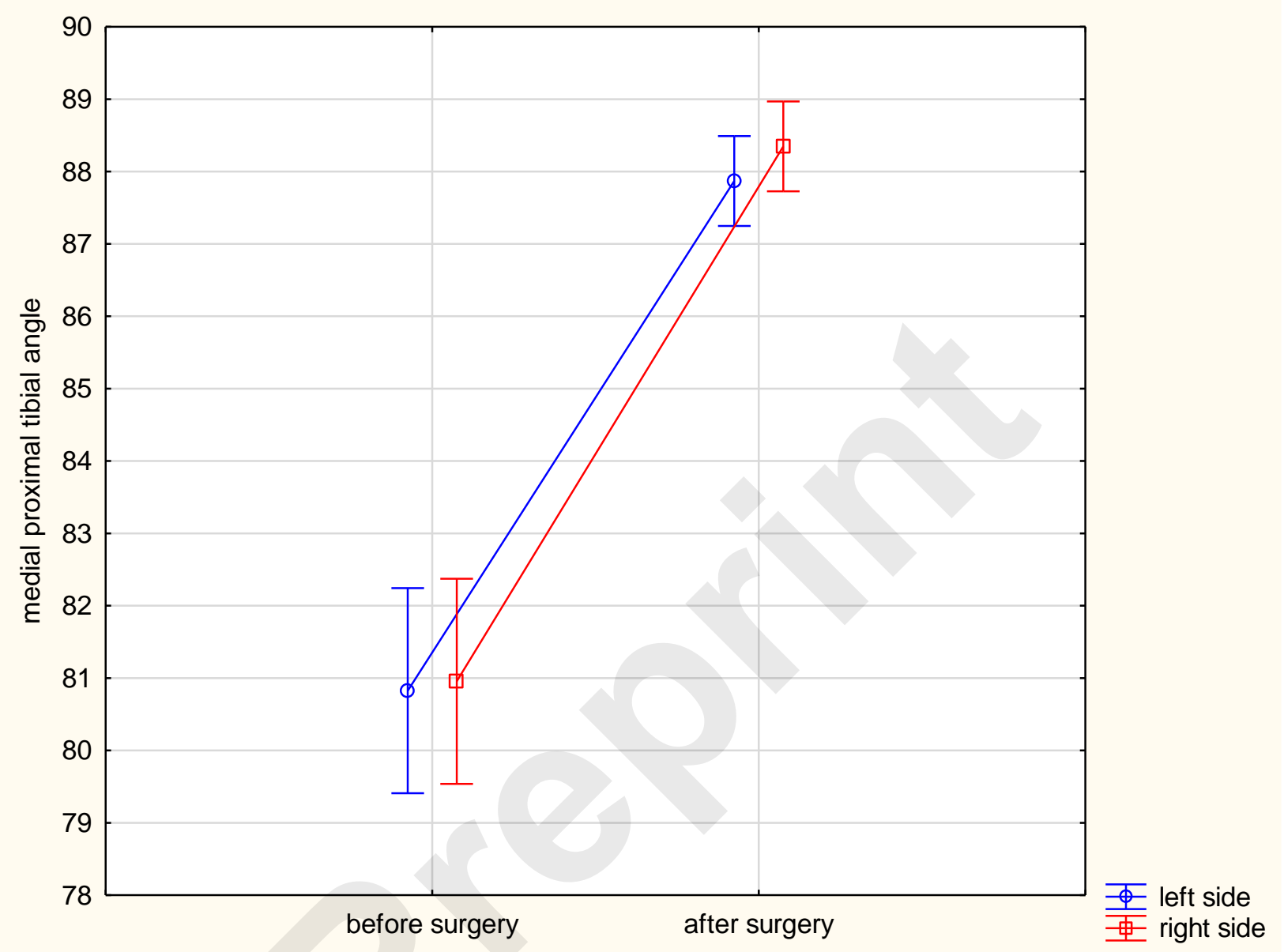




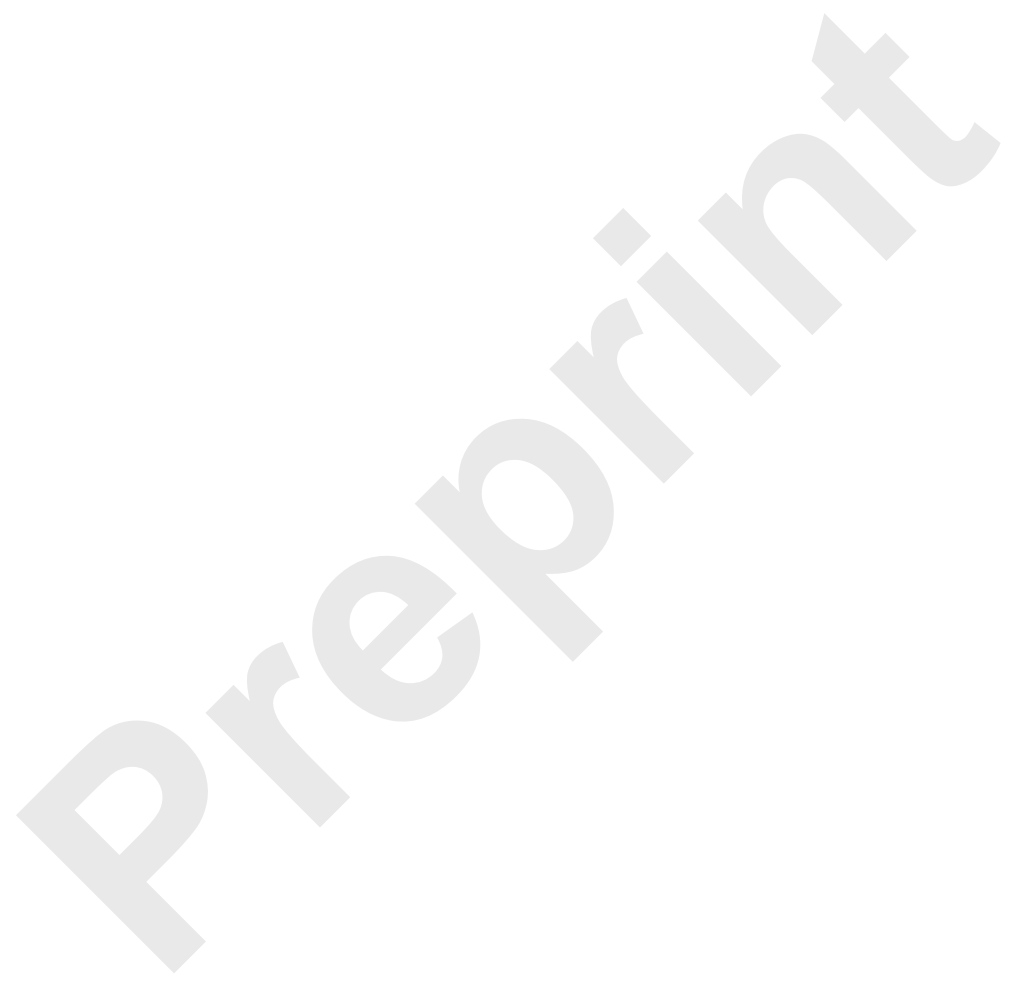




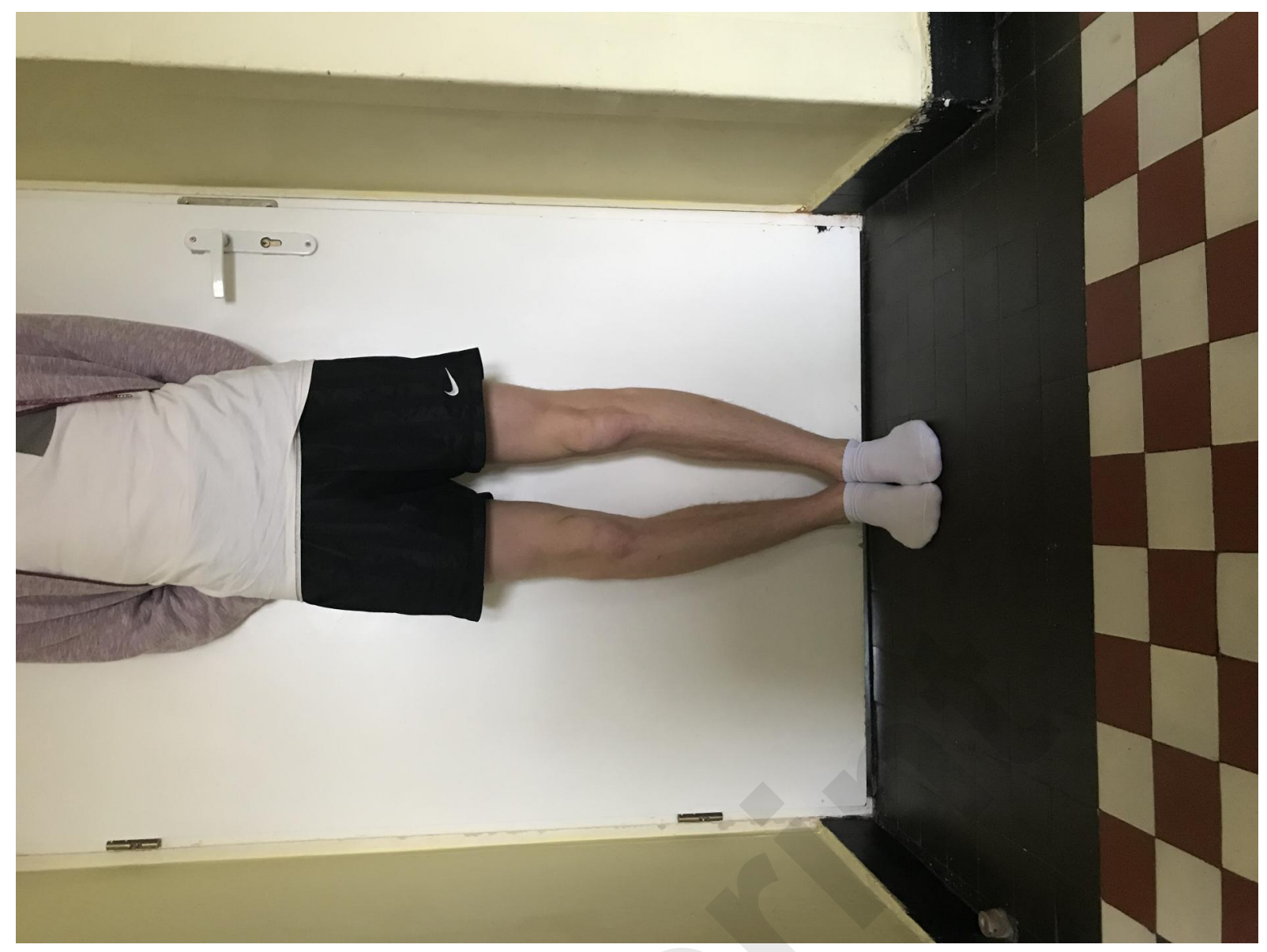

Bilateral varus deformity- ap view 


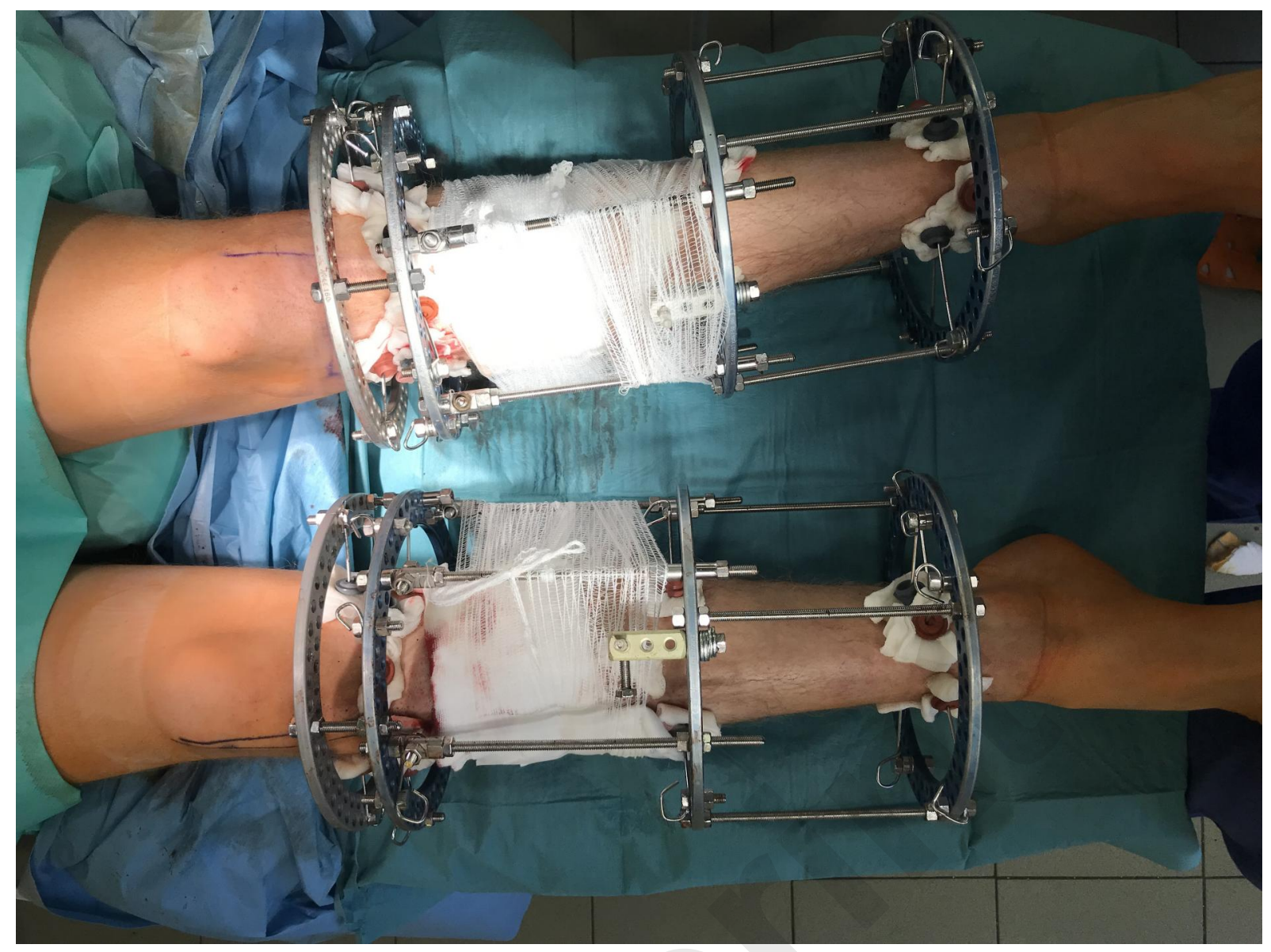

Bilateral correction of varus deformity with Ilizarov External Fixator 
This image is not for diagnostic purposes

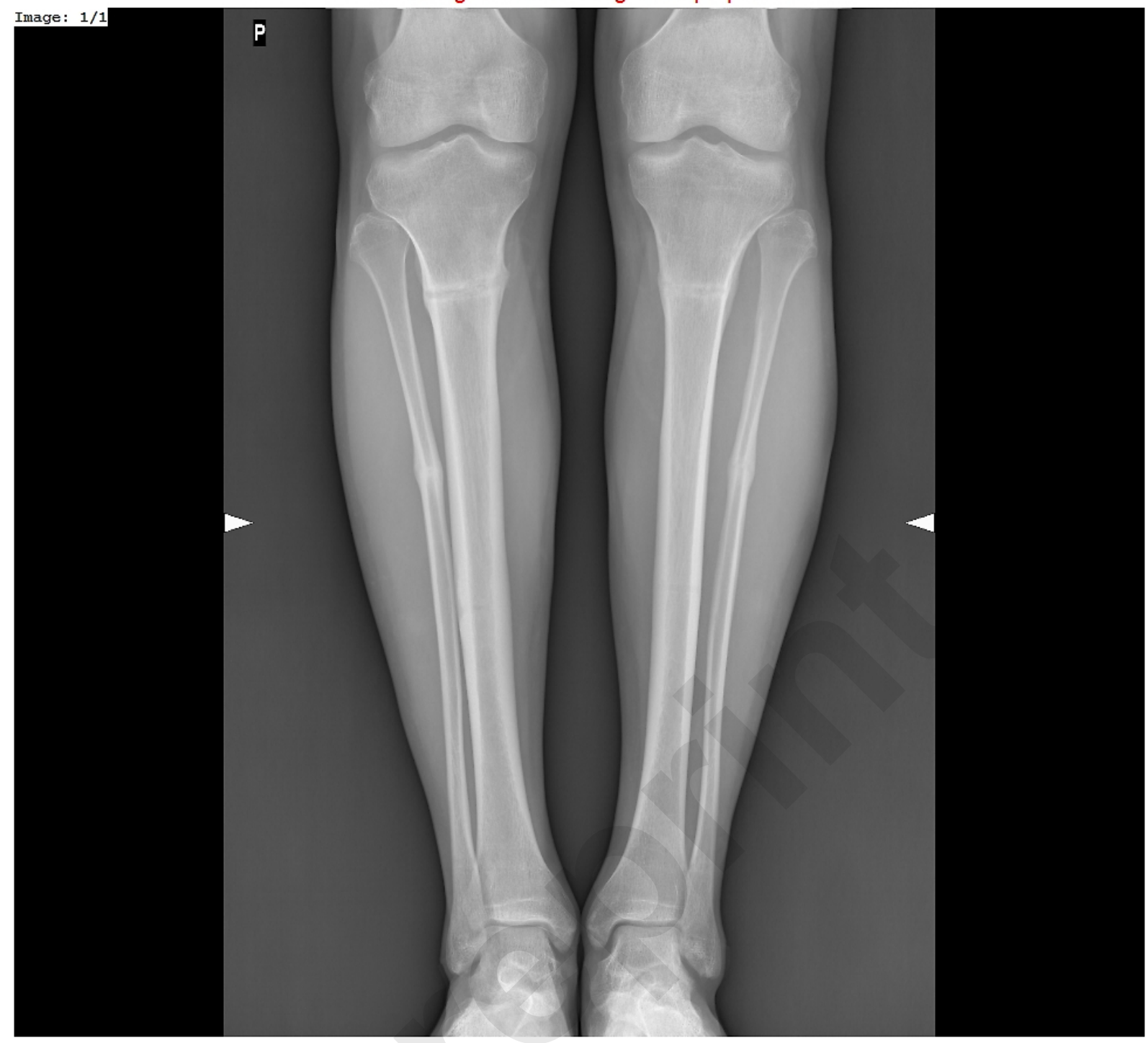

